\title{
Indirect Spectrophotometric Determination of Trace Quantities of Hydrazine
}

\author{
A. M. Haji Shabani, ${ }^{*}$ S. Dadfarnia, and K. Dehghan \\ Department of Chemistry, Yazd Lniversity, P.O. Box 89195-741, Yazd, Iran \\ Received September 27, 2003
}

\begin{abstract}
An indirect. sensitive and accurate method for the deternination of trace amounts of hydrazine is described. The method is based on the oxidation of hydrazine by a known excess of iodate in the presence of hydrochloric acid. The unreacted iodate is used in the oxidation of hydrosylamine to nitrite. Sulfanilic acid is diazotized by the nitrite formed. The resulting diazonium ion is coupled with $\mathrm{N}$-( 1 -naphtllyl)ethylenedianine to form a stable azo dye. which shows an absorption maximum at $540 \mathrm{~nm}$. Hydrazine can be determined in the range of 20-400

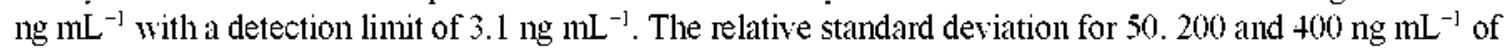
hydrazine is 2.1 .5 and $1.3 \%$. respectively $(n=10)$. The method was applied to the deternination of lydrazine in water samples.
\end{abstract}

Key Words : Indirect method. Spectrophotometry. Hydrazine determination

\section{Introduction}

Hydrazine and its derivatives have been used in industry: agriculture and other fields. including photographic development oxygen scavenging. rocketry, explosives. insecticides and blowing agents for plastics. ${ }^{1}$ However. hydrazine is a local irritant that is readily absorbed through the skin. and its inhalation results in respiratory tract irritation. bronchitis and pulmonary edema. Furthermore. hydrazine is suspected of being a mutagen and carcinogenic compound ${ }^{2}$ Thus. because of its toxicological effects and industrial significance. development of a sensitive method for the determination of trace quantities of hydrazine is of interest.

Several methods are described in the literature for the determination of hydrazine. using different analy'tical techniques. such as spectrophotometry. ${ }^{3.5}$ spectrofluorimetry. ${ }^{10.11}$ voltametry. ${ }^{1213}$ coulometry. ${ }^{14}$ amperometry..$^{15}$ titrimetry. ${ }^{16}$ gas chromatography. ${ }^{17}$ chemiluminescence. ${ }^{i .19}$ ion selective electrode. ${ }^{2 i 2 y}$ and indirect methods. ${ }^{22}$ However most of the proposed methods either lack sufficient sensitivity, ${ }^{16}$ require complicated and expensive instruments, ${ }^{17}$ are time consuming. ${ }^{3}$ or provide high detection limits. ${ }^{11.12}$ Therefore. the need for a sensitive, simple and reliable method for the determination of hydrazine is well recognized.

In the present paper. an indirect. simple. sensitive and precise spectrophotometric method for the determination of trace quantities of hydrazine based on the diazo-coupling reaction is described.

\section{Experimental Section}

Apparatus. Spectral measurements were made with a Jasco Model 7800 double-beam spectrophotometer with 1 cm quartz curettes.

Reagents. All reagents were analytical grade and triply distilled water was used throughout. A hydrazine stock

\footnotetext{
Corresponing Author. Fax: +98-351-82 10644, e-mail: hshabani
} grazduriac.ir solution $\left(1000 \mu \mathrm{g} \mathrm{mL}^{-1}\right)$ was prepared by dissolving 0.3276 $\mathrm{g}$ of hydrazine dihydrochloride (Merck Co.. Germany) in $100 \mathrm{~mL}$ of water. Work solutions were prepared fresh daily by dilution to the appropriate volume with water. A $1000 \mu \mathrm{g}$ $\mathrm{mL}^{-1}$ potassium iodate solution was prepared by dissolving $0.1 \mathrm{~g}$ of $\mathrm{KIO}_{3}$ (Merck) in water and diluting to $100 \mathrm{~mL}$ in a volumetric flask. Suitable dilutions were made to obtain a concentration of $15 \mu \mathrm{g} \mathrm{mL}^{-1}$ of potassium iodate. A $0.25 \%$ hydroxylamine hydrochloride solution was prepared by dissolving $0.25 \mathrm{~g}$ of hydroxylamine hydrochloride (Merck) in water and diluting to $100 \mathrm{~mL}$ in a volumetric flask. A $0.05 \%(\mathrm{w} / \mathrm{v}) \mathrm{N}-(1-\mathrm{Naphthyl})$ ethylenediamine dilydrochloride (NEDA) solution was prepared by dissolving $0.05 \mathrm{~g}$ of NEDA (Merck) in $100 \mathrm{~mL}$ of water. The solution was stored in a brown bottle at $4{ }^{\circ} \mathrm{C}$. The solution was stable for 2 months. A $0.2 \%$ sulfanilic acid solution $(\mathrm{w} / \mathrm{v}$ ) was prepared by dissolving $0.2 \mathrm{~g}$ of sulfanilic acid (Merck) and diluting to $100 \mathrm{~mL}$ in a volumetric flask. Hydrochloric acid $0.25 \mathrm{~mol} \mathrm{~L}^{-1}$ was prepared by diluting the appropriate volume of concentrated acid (Merck) with water.

Recommended procedure. $1 \mathrm{~mL}$ of $0.25 \mathrm{~mol} \mathrm{~L}^{-1}$ hydrochloric acid and $2 \mathrm{~mL}$ of $15 \mu \mathrm{g} \mathrm{mL}^{-1}$ potassium iodate were added to the sample or standard solutions containing $0.2-4 \mu \mathrm{g}$ of lyydrazine in a $10 \mathrm{~mL}$ volumetric flask. The solutions were diluted to $c a .7 \mathrm{~mL}$ with water. Subsequently, $1 \mathrm{~mL}$ of $0.25 \%$ hydroxylamine hydrochloride solution and 1 $\mathrm{mL}$ of $0.2 \%$ sulfanilic acid were added and the mixtures were allowed to stand for $20 \mathrm{~min}$. Then $1 \mathrm{~mL}$ of $0.05 \%$ NEDA was added and the solutions were diluted to the mark with water. The blank solution was prepared by the same procedure and the absorbance was measured against water at $540 \mathrm{~cm}$.

\section{Results and Discussion}

Diazotizaton-coupling reactions followed by spectrophotometric methods have been used routinely for the determination of nitrite. ${ }^{.3 .+4}$ These methods are based on the 
reaction of nitrite with various aromatic amines in an acidic medium to form a diazonium salt, which is used with a coupling agent to produce a highly colored azo compound. Spectrophotometric determination of hydroxylamine by oxidation to nitrite and the formation of azo dye has also been reported. ${ }^{25}$

The aim of this study is to establish a highly sensitive method for the determination of hydrazine. The method is based on the combination of three well-known reactions as follows:

1. Oxidation of hydrazine with a known excess of iodate in hydrochloric acid medium

$$
\mathrm{N}_{2} \mathrm{H}_{4}+\mathrm{KIO}_{3}+2 \mathrm{HCl} \rightarrow \mathrm{KCl}+\mathrm{lCl}-\mathrm{N}_{2}-3 \mathrm{H}_{2} \mathrm{O}
$$

2. Oxidation of hydroxylamine to nitrite by the excess of iodate

$$
2 \mathrm{KIO}_{3}+3 \mathrm{NH}_{2} \mathrm{OH} \rightarrow 3 \mathrm{NO}_{2}^{-}+3 \mathrm{H}^{-}+2 \mathrm{KI}-3 \mathrm{H}_{2} \mathrm{O}
$$

3. Diazotization of sulfanilic acid by the nitrite formed and the coupling of the resulting diazonium ion with NГDA

The red-violet product. $\mathrm{N}-\{1-[4-(4-5 u l f o p h e n y l a z o)$ naphthy]]; ethylenediamine dihydrochloride, has an absorption maxima at $540 \mathrm{~nm}$.

When hydrazine was added in increasing amounts, it consumed more iodate, and thus the concentration of excess iodate was decreased, which resulted in a concomitant fall in nitrite generation. This caused a proportional decrease in the concentration and absorbance of the a7o dye formed in the mixture by an increase in concentration of hydrazine (Fig. 1).

Effect of variables. To establish the best conditions for the formation of azo dye the procedure was optimized by an univariable method (keeping all variables constant except one).

The effect of hydrochloric acid concentration on the absorbance of azo dye was studied. The results show (Гig. 2) that the absorbance increased by an increase in hydrochloric acid concentration up to $0.02 \mathrm{~mol} \mathrm{l}^{-1}$ and then leveled off. A $0.025 \mathrm{~mol} \mathrm{~L}^{-1}$ hydrochloric acid solution was selected to ensure maximum sensitivity.

To optimize the concentration of hydroxylamine, different volumes of hydroxylamine solution $(0.25 \%)$ were added to the mixture under study. It was found that $1 \mathrm{~mL}$ of hydroxylamine solution was sufficient for maximum color

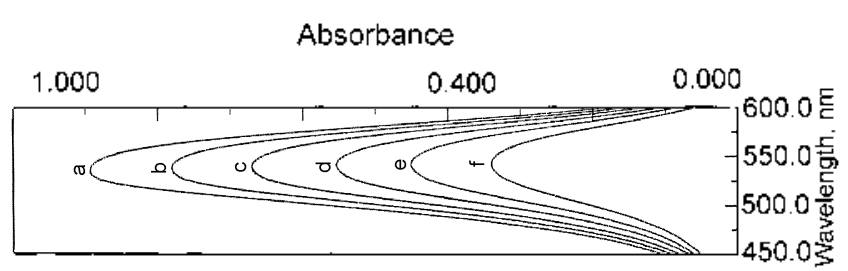

Figure 1. Absorption spectra of the reaction mixture against water in the presence of dillerent concentration of hydrayine: potassium iodate. 3 He ml, $\mathrm{m}^{-1}$ hydrochloric acid. $0.025 \mathrm{~mol} \mathrm{I}^{-1}$; hydroxylamine. $0.25 \mathrm{mg} \mathrm{mL} \mathrm{m}^{-1}$ : sulfanilic acid. $0.2 \mathrm{mg} \mathrm{mL} \mathrm{mL}^{-1}$ : NEDA. 0.05 $\mathrm{mg} \mathrm{mL} \mathrm{';} \mathrm{hydrazine:} \mathrm{a.} 0.0:$ b. 0.1 ; c. 0.2 ; d. $0.3:$ c. 0.4 and f. $0.5 \mu \mathrm{g}$ $\mathrm{mll}^{-1}$

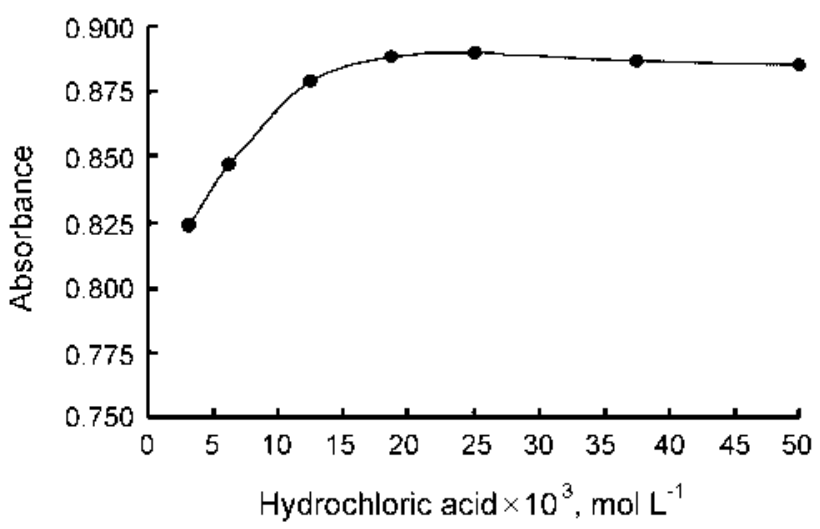

Figure 2. Filect of hydrochloric acid concentration on the absorbance: potassium iodate. $3 \mu \mathrm{m} \mathrm{ml}^{-1}$; hydroxylamine. $0.1 \mathrm{mg}$ $\mathrm{mL}^{-1}$; sulfanilic acid. $0.3 \mathrm{mg} \mathrm{mL} \mathrm{mL}^{-1}$ : NLDA. $0.03 \mathrm{mg} \mathrm{mL}^{-1}$.

development. There was a decrease in absorbance at lower concentration of hydroxylamine, whereas no change in absorbance was observed at higher concentration.

The effect of sulfanilic acid concentration in the range of $0.05-0.6 \mathrm{mg} \mathrm{ml} \mathrm{m}^{-1}$ on the absorbance was studied. The results show that $1 \mathrm{ml}$. of a $0.2 \%$ sulfanilic acid solution gave satisfactory results.

The influence of NEDA concentration on the coupling reaction was studied. The results of $F$ igure 3 indicate that the best absorbance is obtained in the range of $0.03-0.075 \mathrm{mg}$ $\mathrm{mL}^{-1}$. Therefore, a concentration of $0.05 \mathrm{mg} \mathrm{ml}^{-1}$ was selected for further work.

The absorbance was found to be independent of temperature in the range of $15-50{ }^{\circ} \mathrm{C}$. Therefore, as it was more convenient, the procedure was carried out at room temperature. The maximum time required for nitrite generation and diazotization was $20 \mathrm{~min}$.

Analytical performance. Under optimum conditions, a linear calibration graph was obtained over the range of 20 $400 \mathrm{ng} \mathrm{mL} \mathrm{s}^{-1}$ of hydrazine. The regression equation was $\mathrm{A}=$ $0.894-0.001 \mathrm{C}$ ( $\mathrm{C}$ being the hydrazine concentration, $\mathrm{ng} \mathrm{mL} \mathrm{mL}^{-1}$ ), with a correlation coefficient of -0.9997 .

The relative standard deviation for ten replicate analyses

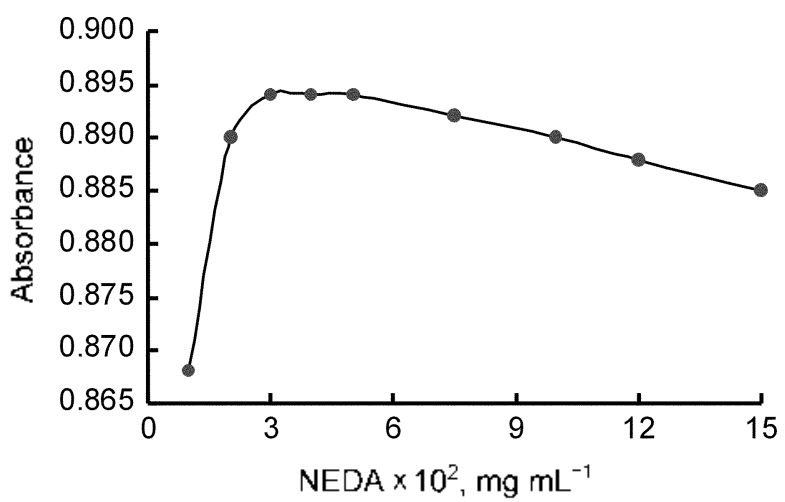

Figure 3. Effect of VEDA concentration on the absorbance:

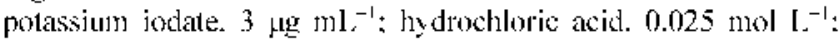
hydroxylamine, $0.25 \mathrm{mg} \mathrm{ml}^{-1}$ : Sulfanilic acid, $0.2 \mathrm{mg} \mathrm{mL}^{-1}$. 
Table 1. Tolerance limit of diverse ions on the determination of 100 ng $\mathrm{mL}^{-1}$ hydrazine by the proposed method

\begin{tabular}{|c|c|}
\hline Intertering ion & $\begin{array}{c}\text { Tolerance linit } \\
\left(\mu \mathrm{g} \mathrm{mL}^{-1}\right)\end{array}$ \\
\hline $\mathrm{Na}^{-}, \mathrm{K}^{-}, \mathrm{Li}^{-}, \mathrm{Ca}^{2+}, \mathrm{Pb}^{2+}, \mathrm{F}^{-}, \mathrm{Cl}^{-}, \mathrm{Br}^{-}, \mathrm{I}^{-}, \mathrm{NO}_{3}^{-}$ & $\geq 100$ \\
\hline $\mathrm{SO}_{4}^{2-}, \mathrm{ClO}_{4}^{-}, \mathrm{CH}_{3} \mathrm{COO}^{-}, \mathrm{Mg}^{2+}$, tartrate & \\
\hline $\mathrm{Mn}^{2+}, \mathrm{NH}_{4}^{+}, \mathrm{Al}^{3-}$, citrate & 50 \\
\hline $\mathrm{Cd}^{-}, \mathrm{Ni}^{-}, \mathrm{Sn}^{2+}, \mathrm{Zn}^{2-}, \mathrm{PO}_{4}^{3-}$ & 10 \\
\hline $\mathrm{Co}^{-}, \mathrm{Fe}^{3-}, \mathrm{CN}^{-}$ & 1 \\
\hline $\mathrm{Cu}^{\hat{*}}, \mathrm{Cr}^{3-}, \mathrm{SCN}^{-}, \mathrm{S}_{2} \mathrm{O}_{3}{ }^{--}$ & 0.2 \\
\hline
\end{tabular}

Table 2. Detemination of hydrazine added to water samples $(n=5)$

\begin{tabular}{lccc}
\hline \multirow{2}{*}{ Sample } & \multicolumn{2}{c}{ Hvdrazine $(\mu \mathrm{g})$} & \multirow{2}{*}{ Recovery $(\%)$} \\
\cline { 2 - 3 } & Added & Found & \\
\hline Tap water & 0.40 & 0.39 & 97.5 \\
& 1.00 & 0.99 & 99.0 \\
& 1.50 & 1.49 & 99.3 \\
\hline River water & 0.40 & 0.41 & 102.5 \\
& 1.00 & 1.00 & 100.0 \\
& 2.00 & 1.99 & 99.5 \\
\hline Well water & 0.40 & 0.38 & 95.0 \\
& 1.00 & 0.98 & 98.0 \\
& 2.00 & 2.01 & 100.5 \\
\hline
\end{tabular}

of standard solution containing 50.200 and $400 \mathrm{ng} \mathrm{mL}-1$ of hydrazine was 2.1 .5 and $1.3 \%$. respectively. The experimental limit of detection calculated as three times the standard deviation of a blank (3s criterion) was $3.1 \mathrm{ng} \mathrm{mL}$ of hydrazine.

Interference. The effects of other ions on the determination of $100 \mathrm{ng} \mathrm{mL} \mathrm{m}^{-1}$ of hydrazine were studied. The tolerance limit was defined as the concentration of added species that causes a relative error less than $3 \%$. The results are summarized in Table 1. At the given concentration no interference was observed in the determination of hydrazine.

Application. The feasibility of the technique for the determination of hydrazine in water samples was examined. $4 \mathrm{~mL}$ of tap. river and well water were spiked with different amounts of hydrazine and the procedure given above was followed. The results are given in Table 2 . The recoveries were close to $100 \%$. indicating that the present method is suitable for the analysis of water samples.

\section{Conclusion}

Hydrazine can be determined with a good accuracy and precision at levels as low as $20 \mathrm{ng} \mathrm{mL} \mathrm{L}^{-1}$ without the need for a preconcentration step. The proposed method is simple and more sensitive than most previously reported spectrophotometric methods.

\section{References}

1. Audrieth. L. F.: Ogg. B. A. The Chemisty of Hydrazines: Tohn Wiley \& Sons. Inc: New York. 1951: pp 225-234.

2. Vemote, E. H: Macewen. J. D: Bruner, R. H.; Haus. C. C.; Kinkead, E. R. Fumdant Appl Toxicol 1985. 5, 1050.

3. Manes. J.: Campillos. P.: Font, G.; Martre, H.: Prognon. P. Anahyst 1987. 112. 1183.

4. Besada. A. Anal. Lett. 1988. 21. 1917.

5. Sire. O. A.: Burno. J. Talanta 1979. 47. 26.

6. Ortega-Barrales. P; Molina-Diaz, A; Pascual-Reguera, M. I.; Capitan-Vallver. L. F. Anal Chin. Acta 1997, 353.115.

7. Wang, S:; Du. L.: Zhang. A.; Liu, D. M fikrochim. Acta 2000. 134. 167.

8. El-Brashy. A. M.: El-Hussein. L. A. Anal. Lett. 1997. 30.609.

9. Safavi. A.: Ensafi. A. A. Anal Chim Acta 1995. 300. 307.

10. Ensafi, A. A.; Naderi, B. Taloma 1998. +7.645.

11. Balconi. M. L.: Sigon, F.: Borgarello, M.: Ferraroli. R.: Realini. F. Anal Chm. Acta 1990, 23t, 167.

12. Yang. M.: Li. H. L. Talanta 2001. 55. 479.

13. Wang. T.: Taha. Z. Talonta 1988. 35.965.

14. Athanasio-Malaki. E.: Koupparis. M. K. Talanta 1989. 36.431.

15. Ikeda, S.: Sutake. H.: Kohri, Y. Chent. Lett 1984, 6.873.

16. Huamin. J.: Weiving, H.: Erkany, W. Talanta 1992. 39.45.

17. Vatsala, V. Bansal, V. Tuli, D. K.: Rai. M. M. Jian. M. M. Stivastava. S. P.: Bhatnagar. A. K. Chromatographia 1994. 38.456.

18. Lv. T.: Huang. Y.: Zhang. Z. Anal Lett. 2001.34 . 1323.

19. He. Z.: Liu. X.: Luo. Q.: Tang. H.: Xu. Y.: Chent. H.: Zeng. Y. Microchem. J. 1996, 53.356 .

20. Gawargious. Y. A.; Beseda, A. Talanta 1975. 22.757.

21. Rateliffe. N. M. Anol Chim . Acta 1990. 239, 257.

22. Safavi. A.: Abdollahi. H.: Sedaghatpour. F.: Hormo $<i$ Ne $\iota$ ad. M. R. Talanta 2003. 59. 147.

23. Moorcroft. M. T.: Davis. T.: Comptonl. R. G. Talanta 2001. 54. 785 .

24. Sreekumar. N. V: Narayana, B.; Hegde. P.: Manjunatha, B. R:; Sarojini, B. K. Microchem. J. 2003, 74. 27

25. Verma. P.: Gupta. V. K. Talonta 1984. 31. 1013. 